\title{
DEVELOPING THE OLD PART OF MUKALLA CITY (AL SALAM AND AL SAAIADIN QUARTER AS A CASE STUDY)
}

\section{Khaled Nasser Barashed}

Department of Architecture, Faculty of Engineering \& Petroleum, Hadhramout University for Science \& Technology, Yemen

(Received January 17, 2005 Accepted March 21, 2005)

The escalating need for modern services in the cities nowadays due to the extensive use of cars and the great increase in the human concentration and density and by far the increase in real estate values greatly instigated these changes. Nevertheless, the basic urban tissue did not assimilate all these changes in a manner that may allow the functions expected of them to be executed. This resulted in the failure of a portion of the services as well as in the change of the nature of the urban tissue in haphazard way during this particular period. Thus, the qualitative environmental level in the area was greatly affected.

The city of Mukalla, which is the capital of the governorate of Hadhramout (Yemen), is situated on the coast of the Arabian Sea on longitude (49.23) East and latitude (14.39) North. Throughout many a consecutive period in time, the city had passed through many variation that changed its features and its basic nature to great extent.

Therefore, this study tackles the most important problems the area is suffering from, for the sake of outlining the nature of these problems and attempting by far to give general planning and designing recommendations for the development of the area based upon the methodical assessment of the elements of the urban tissue in the old sector of Mukalla.

KEYWORDS: Al Salm, Al saaiadin Quarter, Mukalla Developing,, Rehabilitation, Urban Planning,

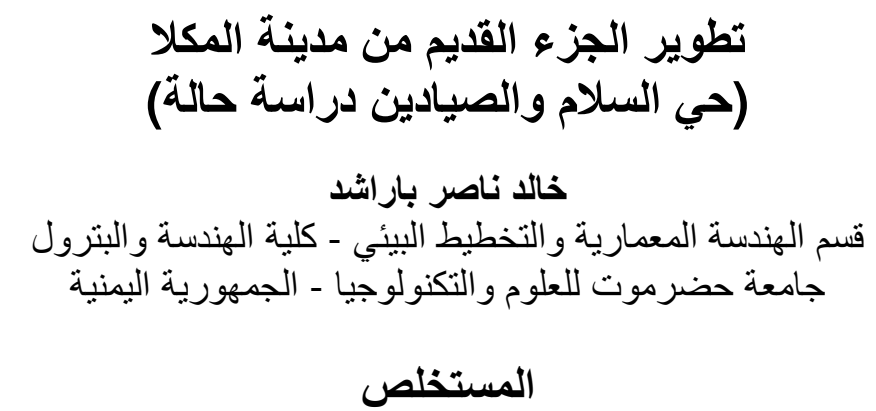

أدى زيادة الكثافة البشرية والبنائية والاستخدام المكثف للسيار ات في الآونـة الأخيرة إلى تتامي الحاجـة

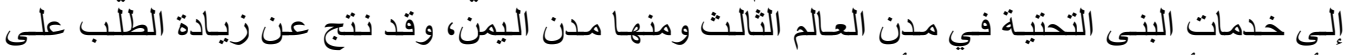

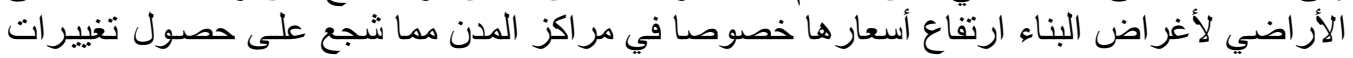


كبيرة لم يستطع النسيج الحضري الأساسي في أغلب الأحيان من استيعابها بشكل يسمح بأداء الوظـائف

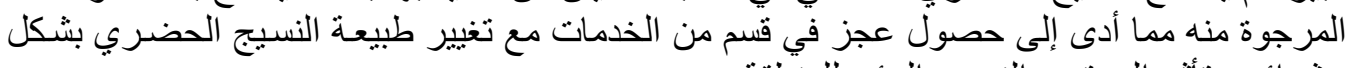

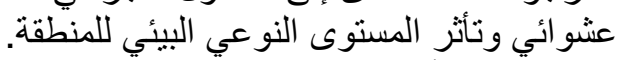

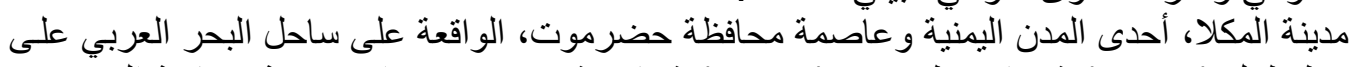

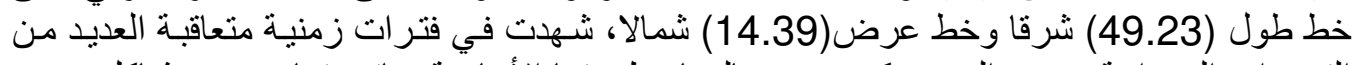

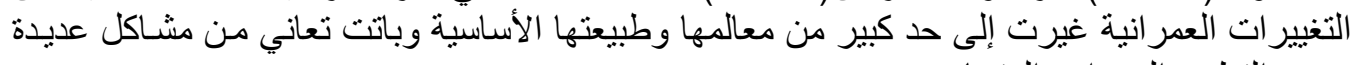
بسبب النطور العمر اني المنسارع.

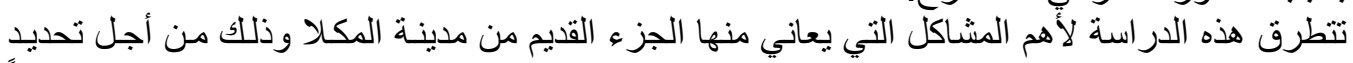

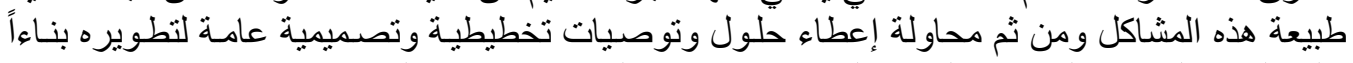

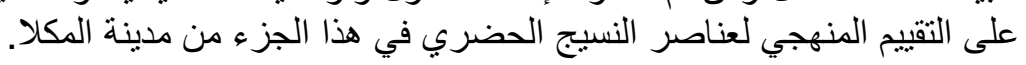

الكلمات المفتاحية: حي السلام، حي الصيادين، مدينة المكلا، تطوير، تأهيل، تخطيط حضري.

\section{1- أهداف الدراسة}

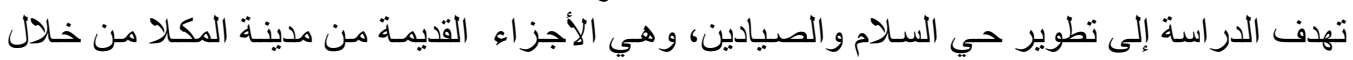

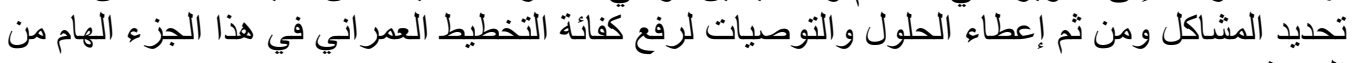

\section{2- منهج الدراسة}

المدينة.

لتحقيق الأهداف المرجوة من الدراسة انتهج البحث أسلوب المنهج العلمي بشقية التحليلي و الميداني.

\section{3 - مراحل التطور العمراني لمدينة المكلا}

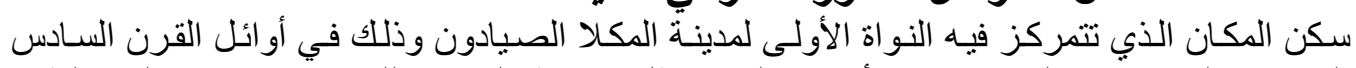

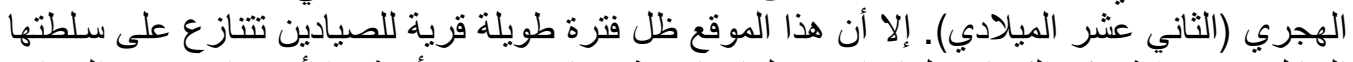

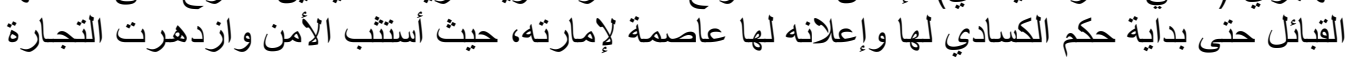

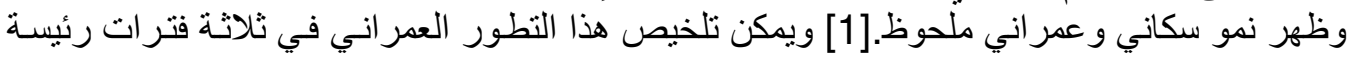
هي:

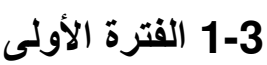

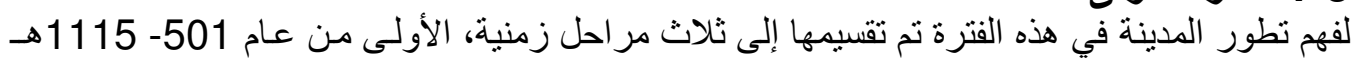

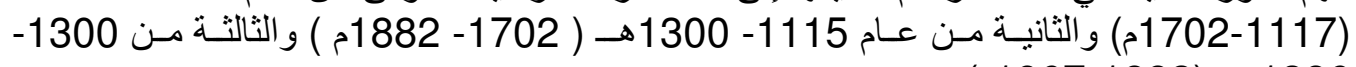
1386 هـ (1882 (1967-182م)

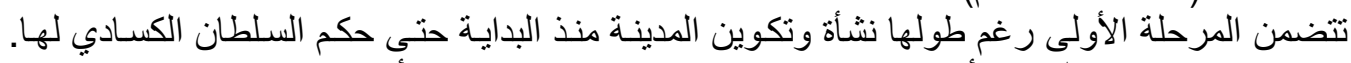

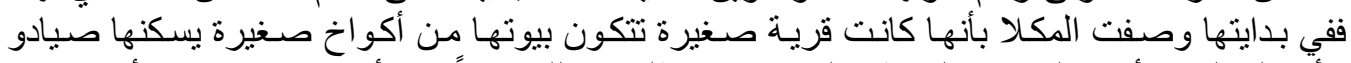

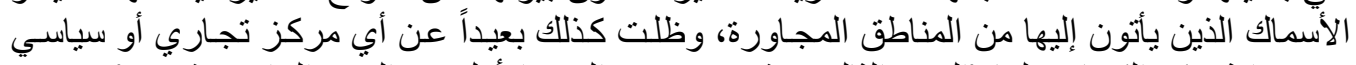

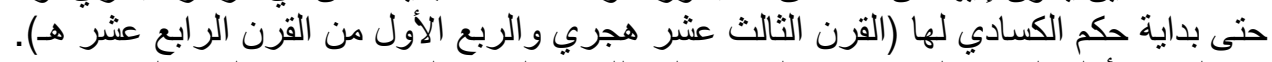

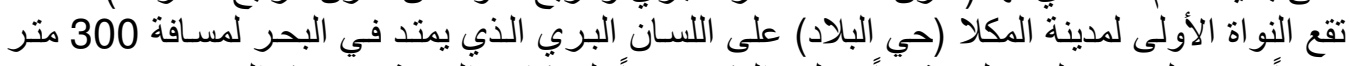

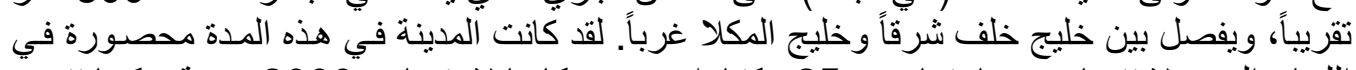

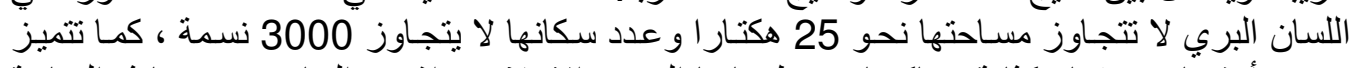

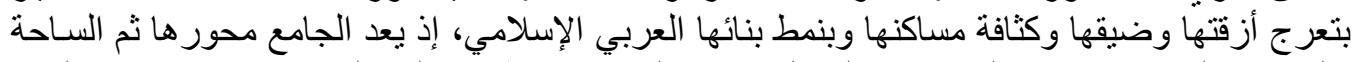

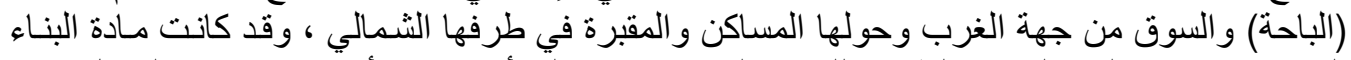

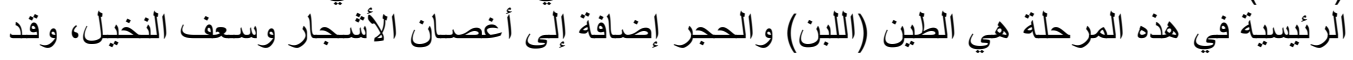




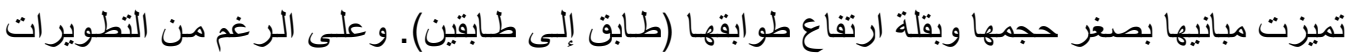

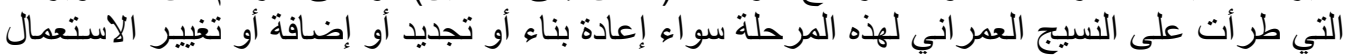

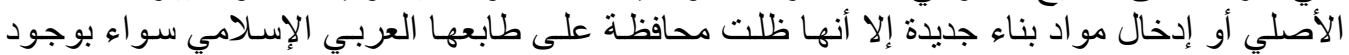

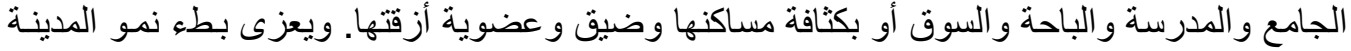

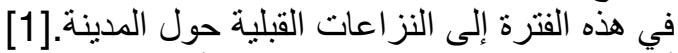
أمًا المرحلة الثانية فهي فترة حكم الأسرة الكسادية للمكلا، وقد تميزت هذه الفترة بالاستقرار و الازدهار

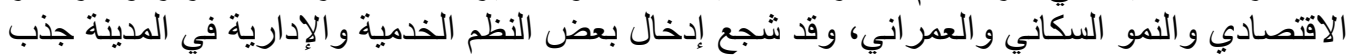
السكان من ساحل حضرموت وداخلها. كما وفدت إليها جاليات هندية وصورمالية وكينية وحبشية

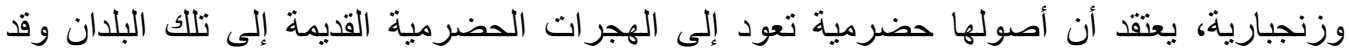

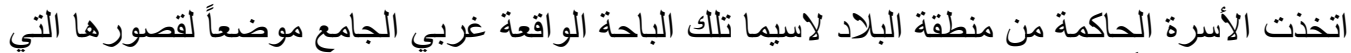

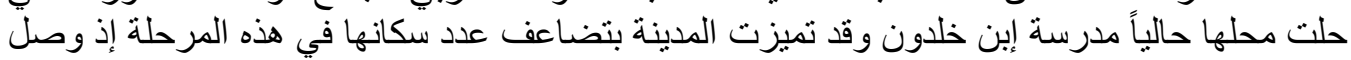

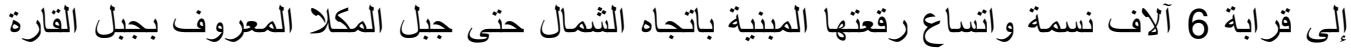

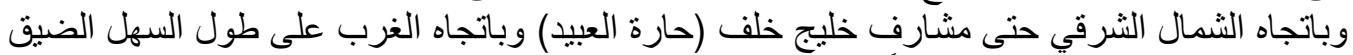

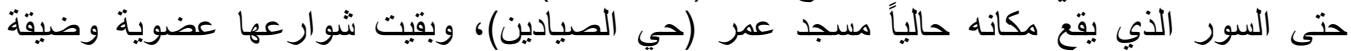

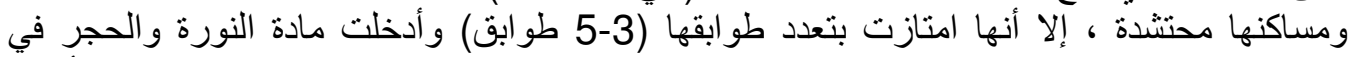

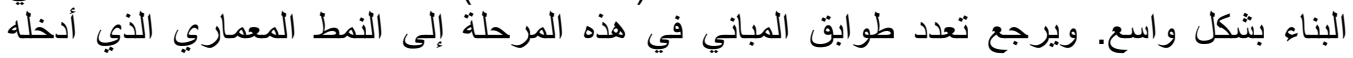

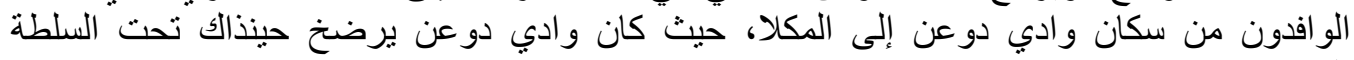

الكسادية. [2] الكونية

في المرحلة الثالثة وهي المدة التي حكم فيها السلطان القعيطي المكلا، حيث شهدت المدينة في بدايتها

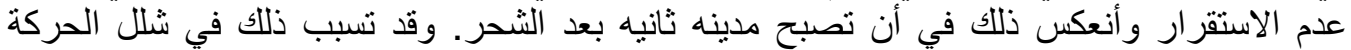

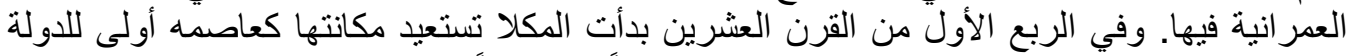

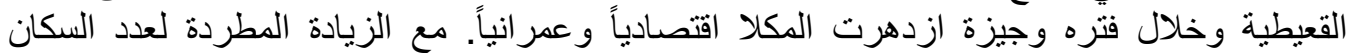

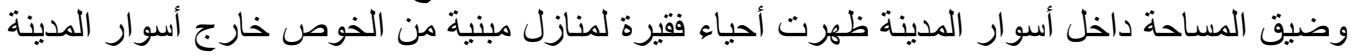
وهو ما كان يعرف بيرع السدة (خارج بوابة المدينة) في نفس الحي الذي يسمى اليوم بحي السلام.

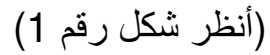
و قد ظهرت الحاجة لتوسعة المدينة في اتجاه الغرب - خارج الأسوار - لعدة أسباب يمكن إيجازها

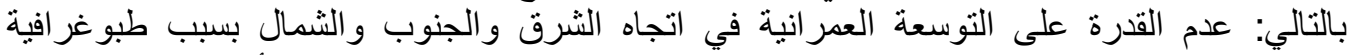

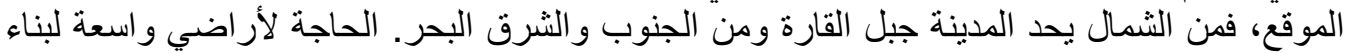

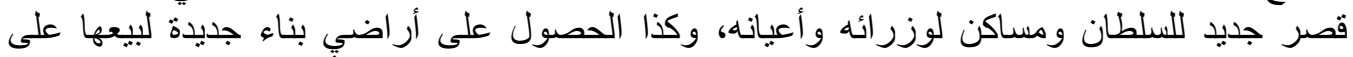

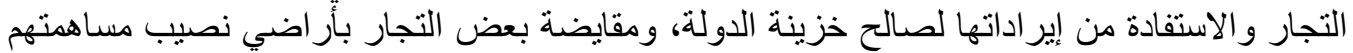
في بناء بعض المباني الحكومية، إنشاء مدينة حديثة لاستيعاب وسائل النقل الحديثة (السيارة)، وكذا لإنة لتخفيف الازدحام على المدينة القديمة. و لتلك الأسباب أنشئ السلطان القعيطي قصراً جديدا وسور آخر - بعد هدم القديم - على مشارف و ادي التي

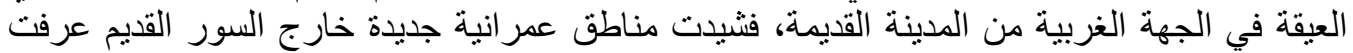

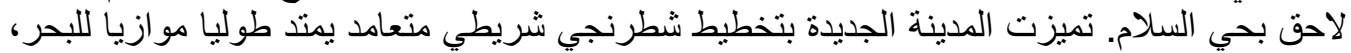

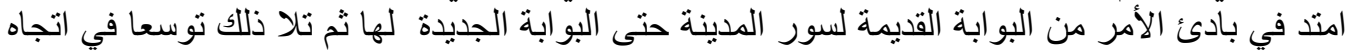

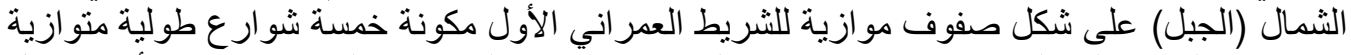

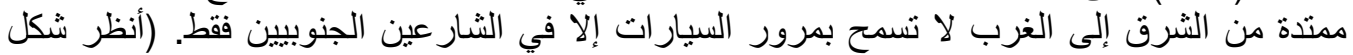

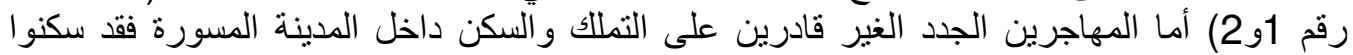

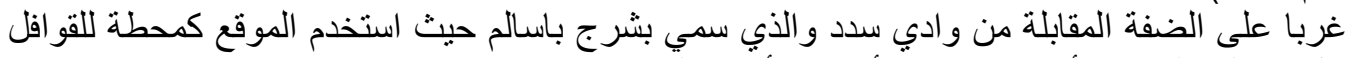

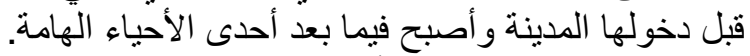

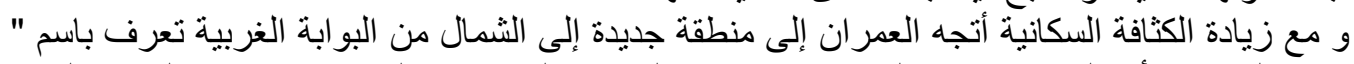
ديس المكلا " أو الديس إضافة إلى هضبة شعب البادية والمعروفة بالرزميت (وهي كلمة إنجليزية 
محرفة معناها regiment) حيث نواجدت بها ثكنات ومعسكرات جيش البادية الحضرمي و الثرطة [3] القعيطية.

و في فترة الحرب العالمية الثانية نم بناء مطار لسلاح الجو الملكي البريطاني في فوه ومطار آخر آلخر

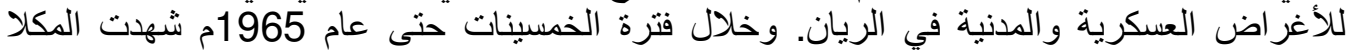
وضو احيها (الديس و الثر ج) حركَه عمر النية كبيره وسريعة فئرة

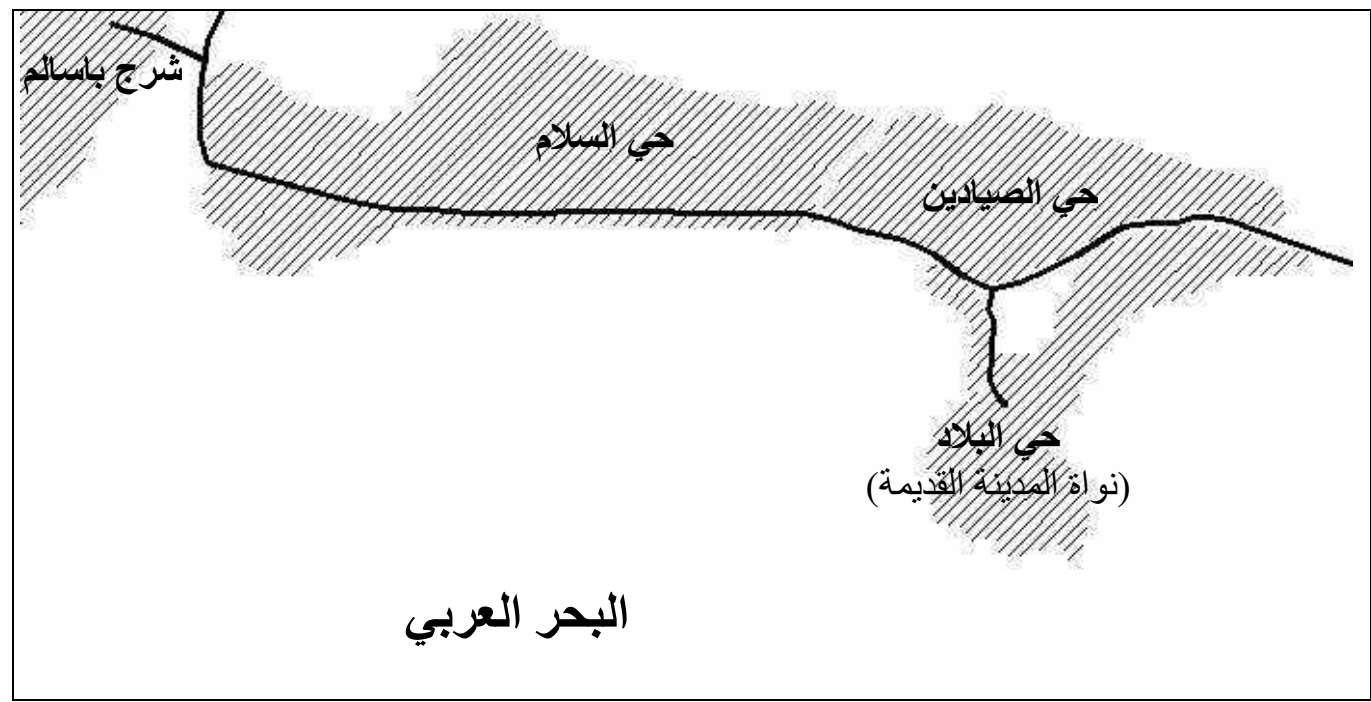

شكل رقم 1: خريطة دياجر امية توضح النواة القديمة لمدينة المكلا و اتجاه نمؤ المدينة في الفترات

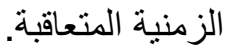

\section{2-3 2-3 الفترة الثانية}

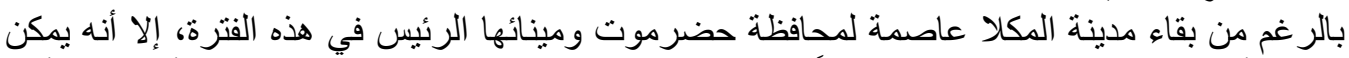

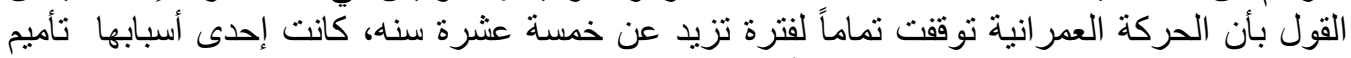

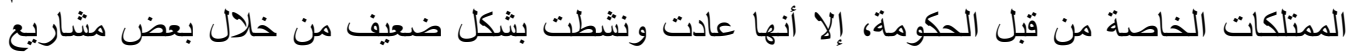

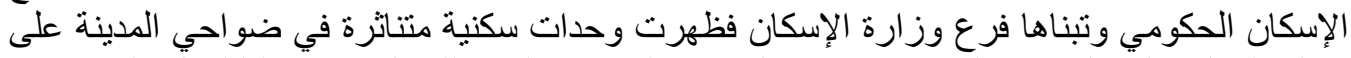

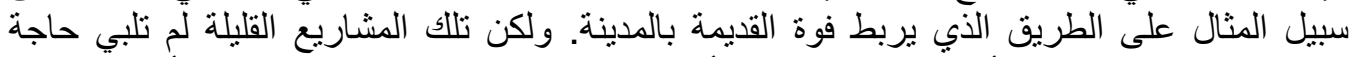

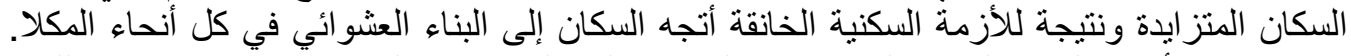

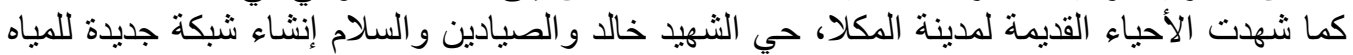

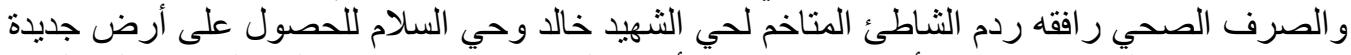

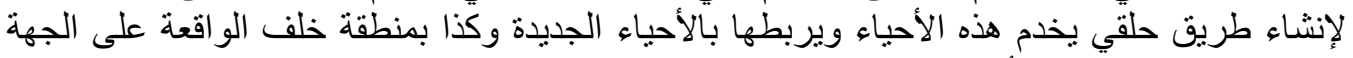

الثرقية من جبل القارة. (أنظر شكل رقم 1) 


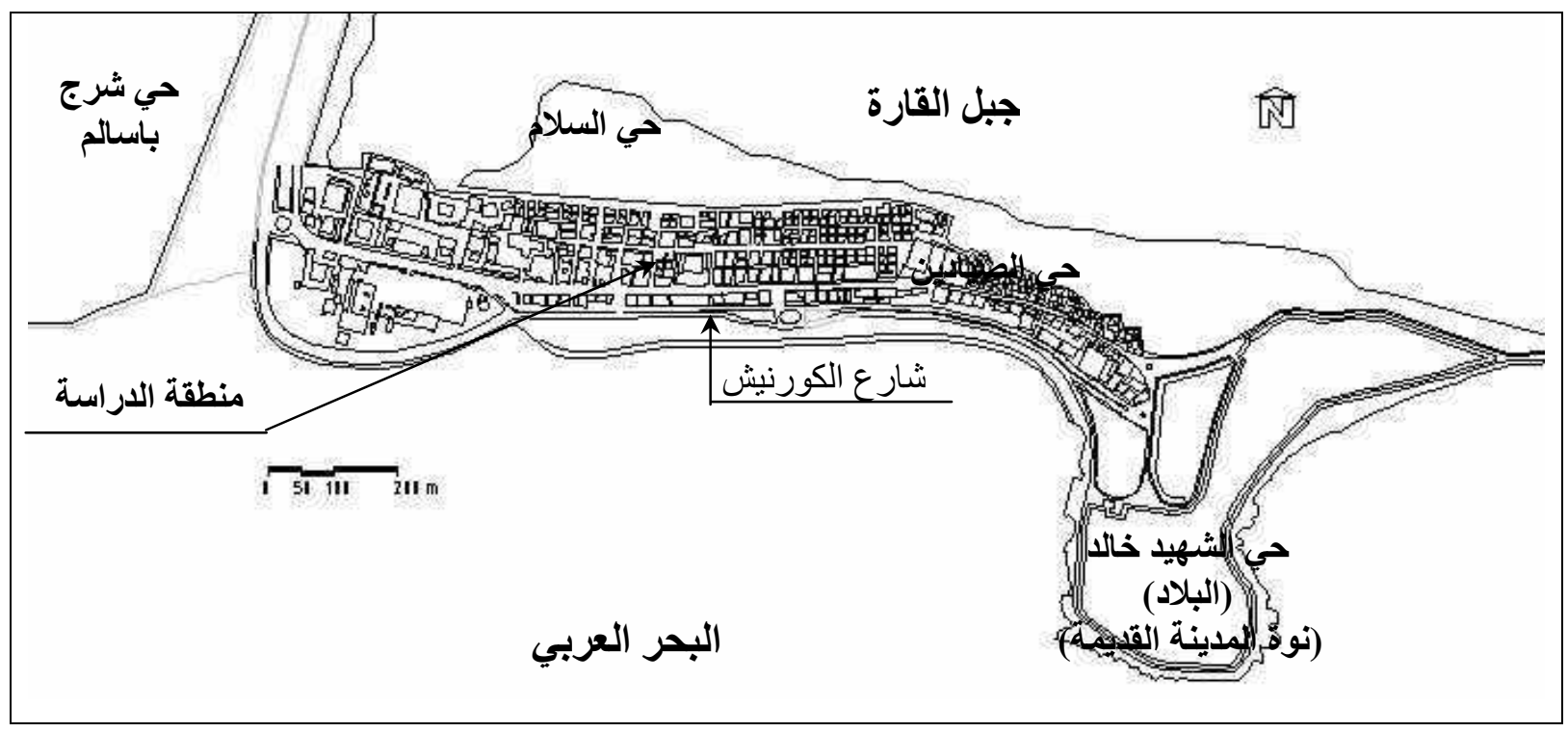

شكل رقم 2: خريطة توضح منطقة الدر اسة من باقي الأحياء القديمة لمدينة للمكلا.

\section{3-3 - 3 الفترة الثالثة}

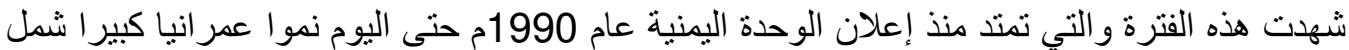

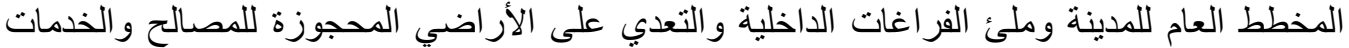

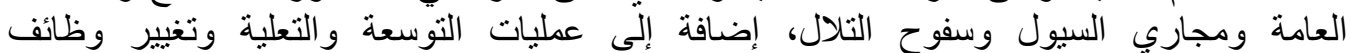

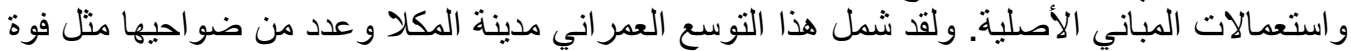
و الحرشيات وبويش وروكب ومناطق أخرى. ولقد و اكب هذه الطفرة العمرانية توسيع لخدمات البنية التحتية كالطرقات و الكهرباء و الماء، إلا أنه وبالر غم من ون ذللك ظلت المدينة تعاني من نقص شديد في في بعض جو انب تلك الخدمات.

\section{4- واقع حال التخطيط العام}

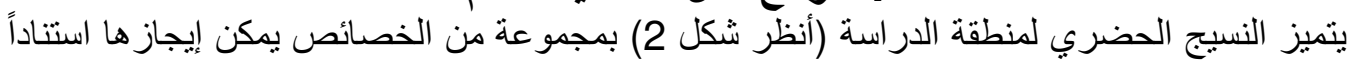

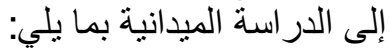

\section{1-4 - 1-4 استعمالات الأرض الأرض}

عند در اسة استعمالات الأرض لألأغر اض اضل السكنية والتجارية للموقع لوحظ سيطرة الاستعمال السكني-

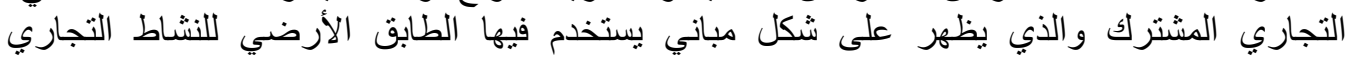

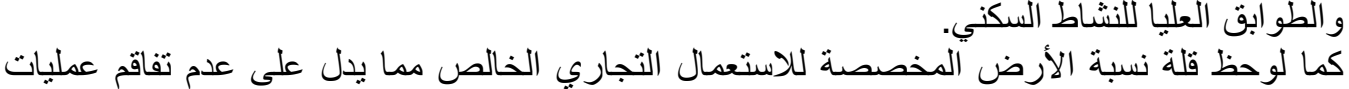

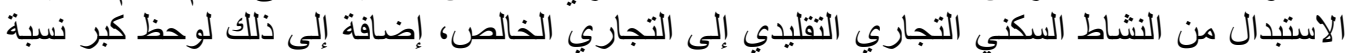

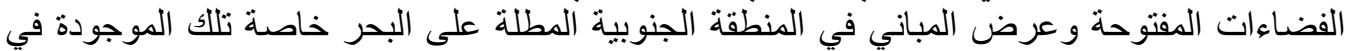
شارع الكورنيش لتقل كلما اتجهنا نحو الداخل في اتجاه الجبل. أما ما يخص الحسل الحركة الآلية والمشاة

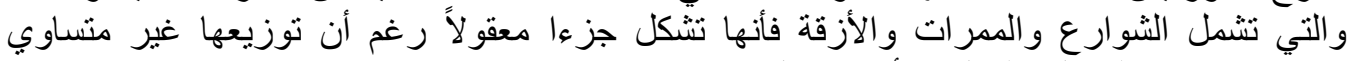
ويتناقص باتجاه الثمال (الجبل). (أنظر شكل رقم 


\section{2-4 - 2-4 كثافة النسيج العمراني}

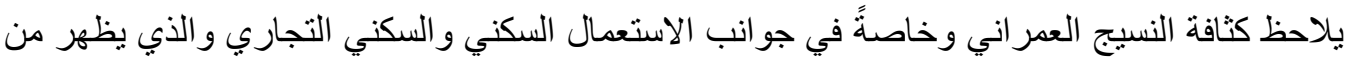

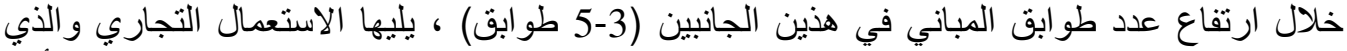

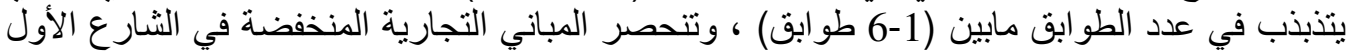

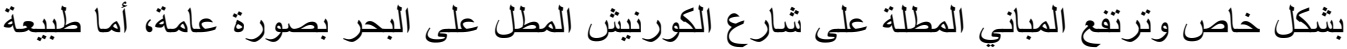

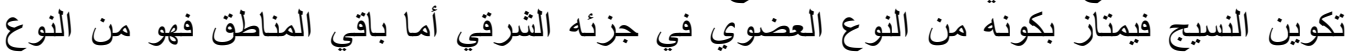

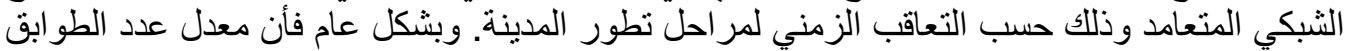

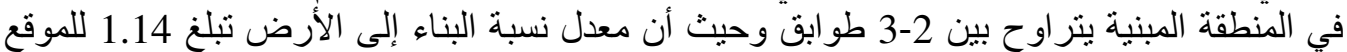

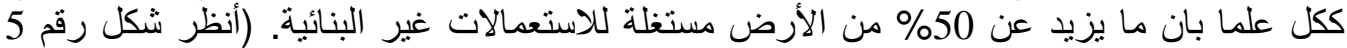

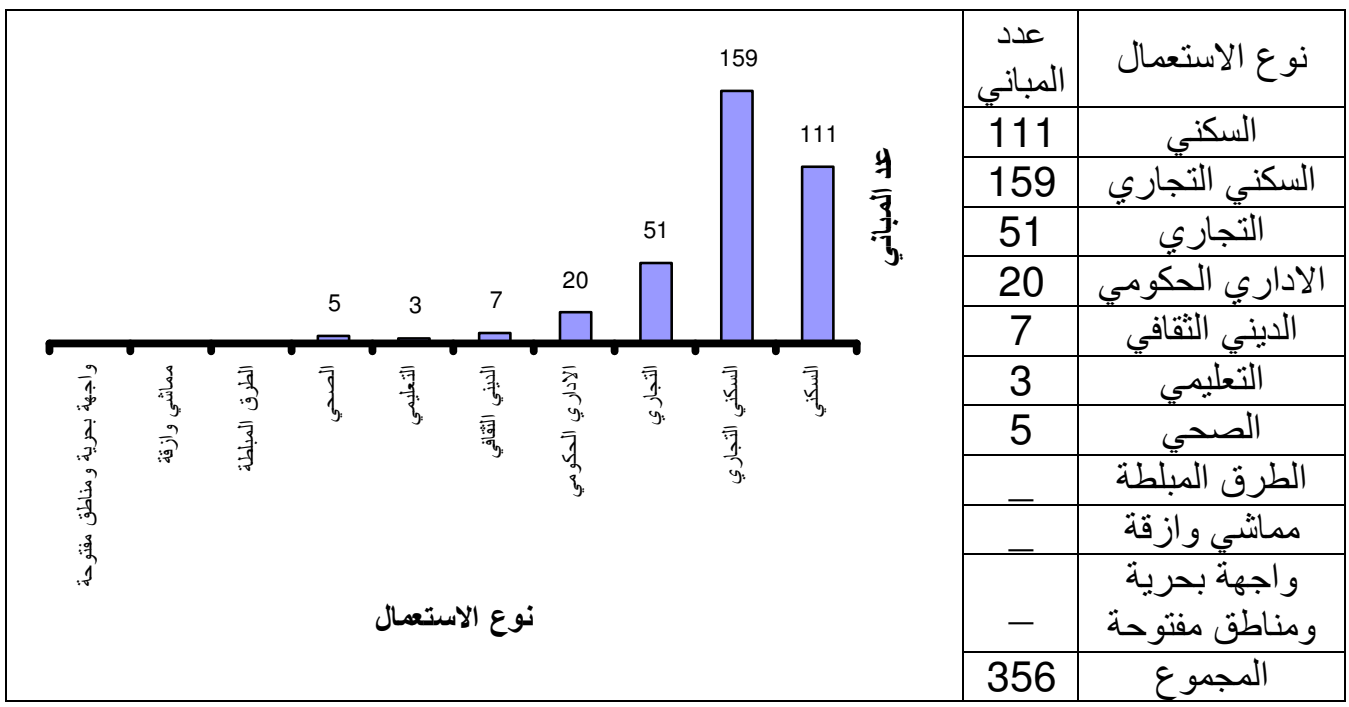

شكل رقم 3: يوضح عدد المباني في الموقع.

\section{5- نسب الاستعمال ومخطط الحركة في الموقع}

تم تقسيم منطقة الدراسة لأغراض التحليل الدقيق إلى ثلاثة أثرطة أفقية متوازية ابتداء من المنطقة

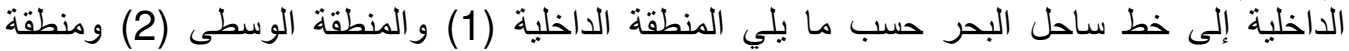

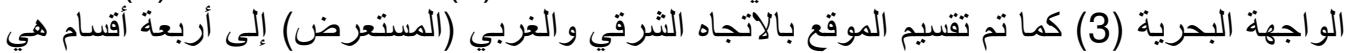

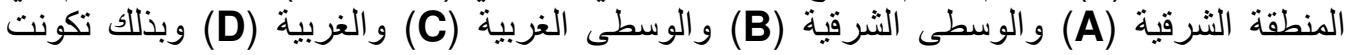
10مناطق (انظرشكل رقم 8).

\section{1-5 نسب استعمال الأرض الئ}

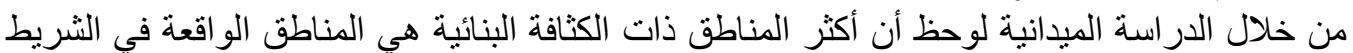

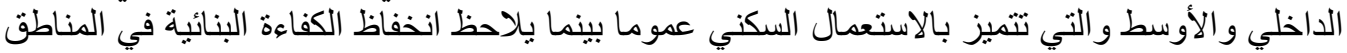


المستقلة في المنطقتين (C3, B3) بشكل خاص وكبر نسبة الفضاءات المفتوحة و التي تأتي من خلال

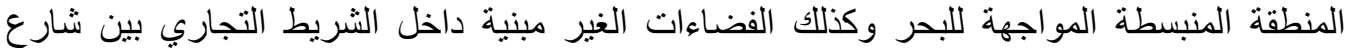

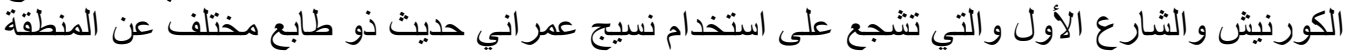

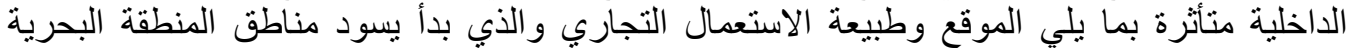

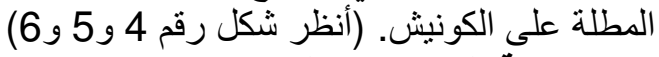
2-5 حركة السيارات والمشاة

يتميز الموقع بوجود ثلاثة محاور رئيسية لحركة السيارات وهي شارع الكورنيش الأكثر مساحة

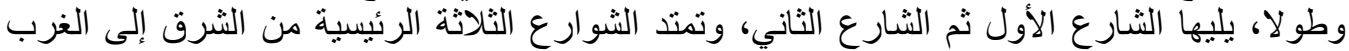
تربطها ببعضها شو ارع و أزقة ضيقة تتعامد معها ممتدة من الجنوب الثنا إلى الثمال.

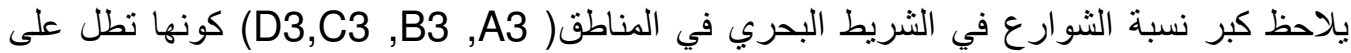

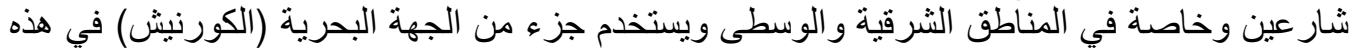

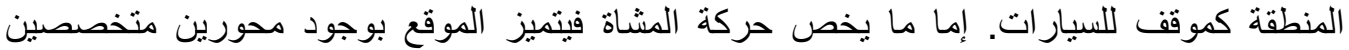

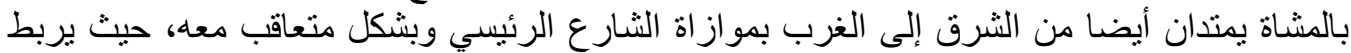

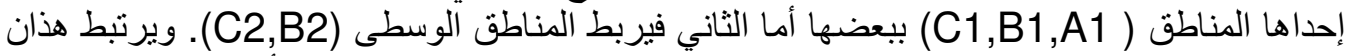

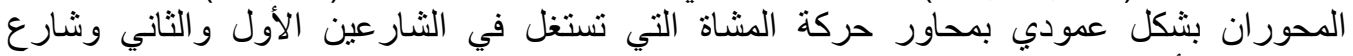
الكورنيش. (أنظر شكل رقم 8) - ان

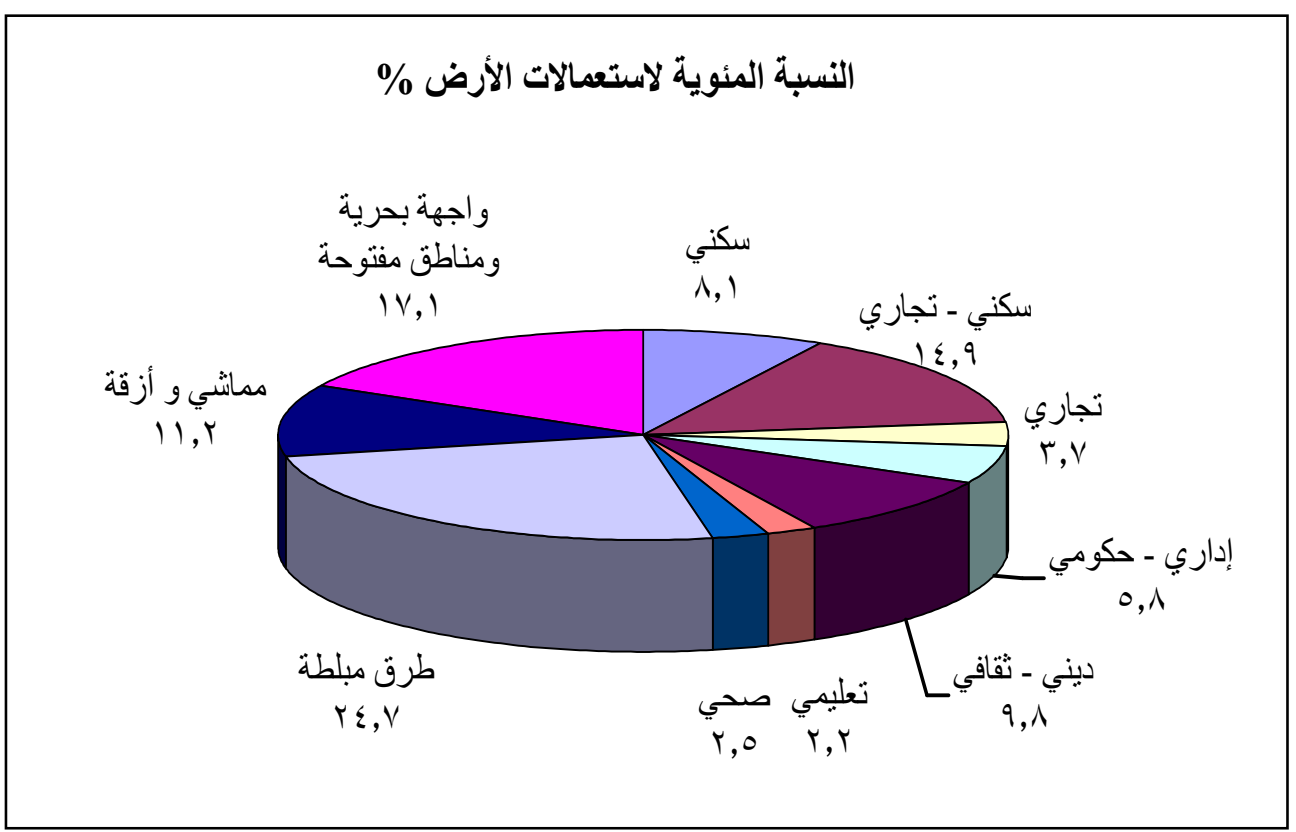

شكل رقم 4: رسم بياني يوضح استعمالات الأرض في منطقة الدر اسة. 


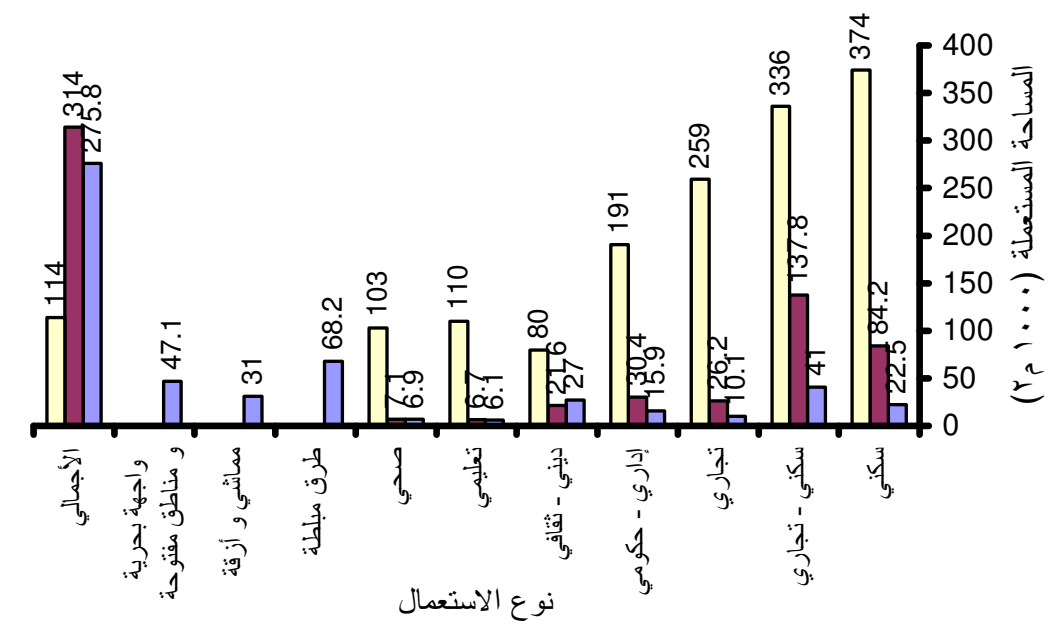

مساحة الأرض

$\left(r^{2} 1 \cdots\right)$

مساحة البناء

$\left.\left(r_{p}\right) \cdots\right)$

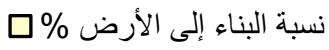

شكل رقم 5: رسم بياني يوضح المساحة المبنية ونسبتها إلى الأرض.

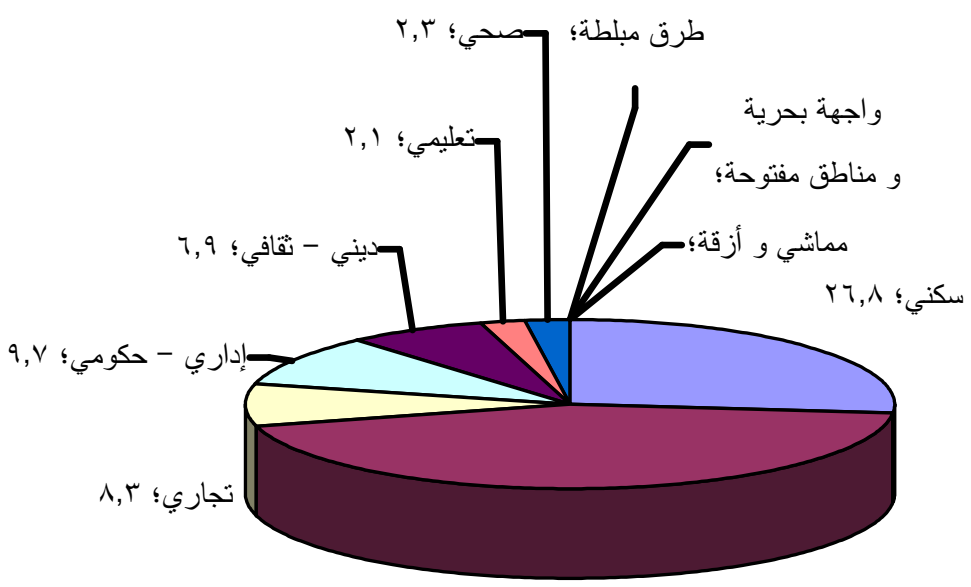

$$
\text { سكني - تجاري؛ } 9 \text {, }
$$

النسبة المئوية للبناء

شكل رقم 6: رسم بياني يوضح النسبة المئوية للبناء في منطقة الدر اسة. 


\section{6- - استخدام المباني وحالتها الإنثائية}

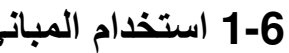

كما ورد سابقا واستتاداً إلى الدراسة الميدانية لوحظ أن استخدام المباني في منطقة الدراسة يتميز بما يلي

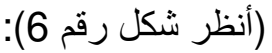

أ- تسلسل النشاط السكني، والسكني التجاري، والتجاري بشكل يتميز بانتقالية متسلسلة من المنطقة الداخلية إلى الواجهة البحرية (الكورنبش).

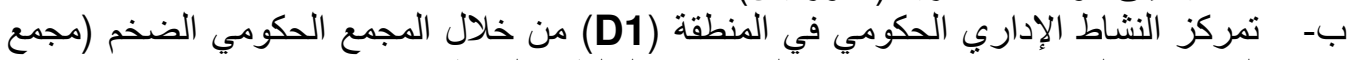
القصور) و الذي يعود جز اء كبير منة لفترة الإد حكم السلطان القعيطي.

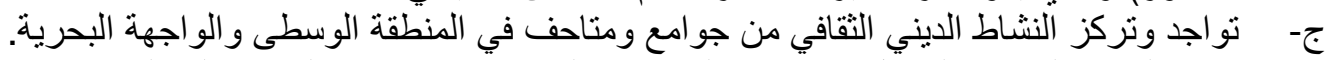

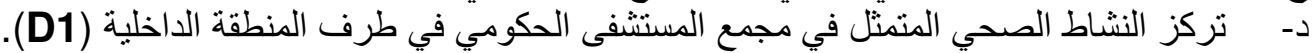

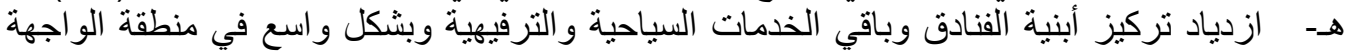

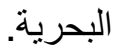
و - المنطقة الوسطى ذات نشاط متقارب وخاصة الوسط (C2,B2).

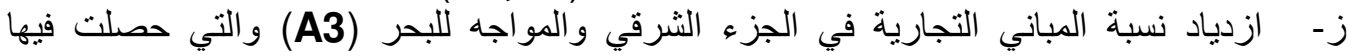
تغير ات كبيرة. ح- تركز نشاط الخدمات التعليمية والصحية في المنطقة الغربية والتي بنيت في فترة قريبة نسبيا

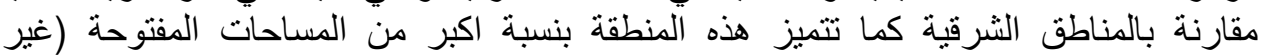

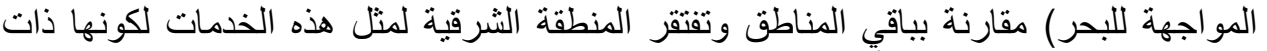

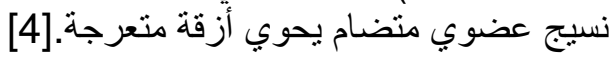

2-6 - 2-6 الحالة البنائية من خلال الدر اسة الميدانية (أنظر) يمكن استنتاج مايلي: أ- وجود نسبة لا بأس بها من المباني بحالة جيدة وجيدة جدا في منطقة الواجهة البحرية نتيجة البناء

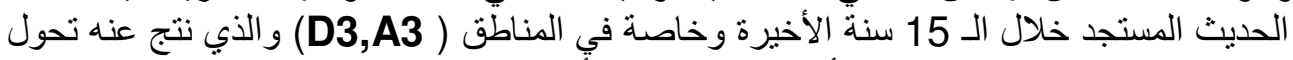

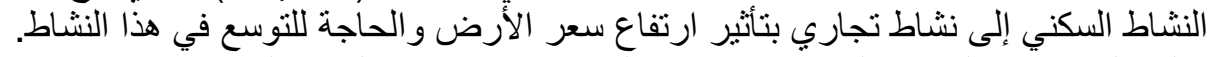

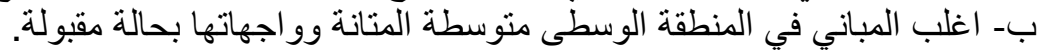
ج- النسبة العظمى من المباني ذات الحالة دون الوسط تقع في الثريط الداخلئ وانئ واغلبها تتألف من مباني

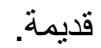
د- تركز المباني ذات الحالة الإنشائية الرديئة في المنطقة الغربية (D3,D1) وبصورة فالئية خاصة في

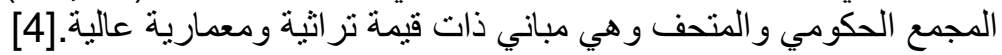

\section{7- التوقعات المستقبلية}

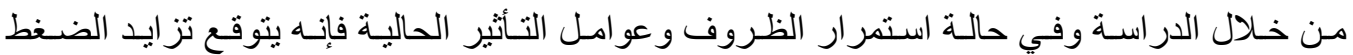

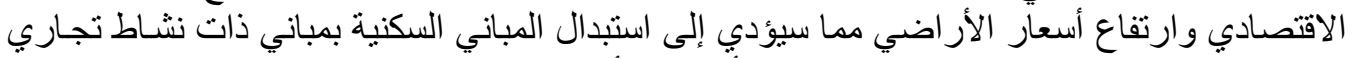

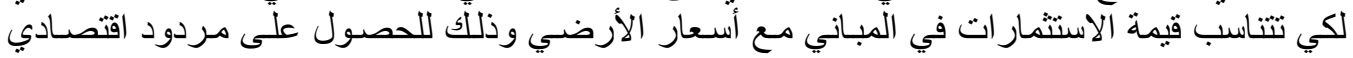

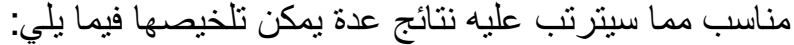

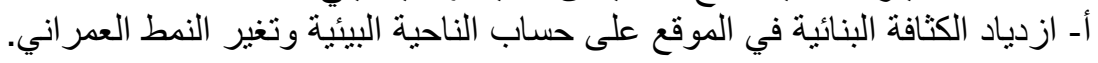




\section{جيدة جيدة جدا رديئة \\ $\% 1 \% \leqslant \quad \% \wedge$}

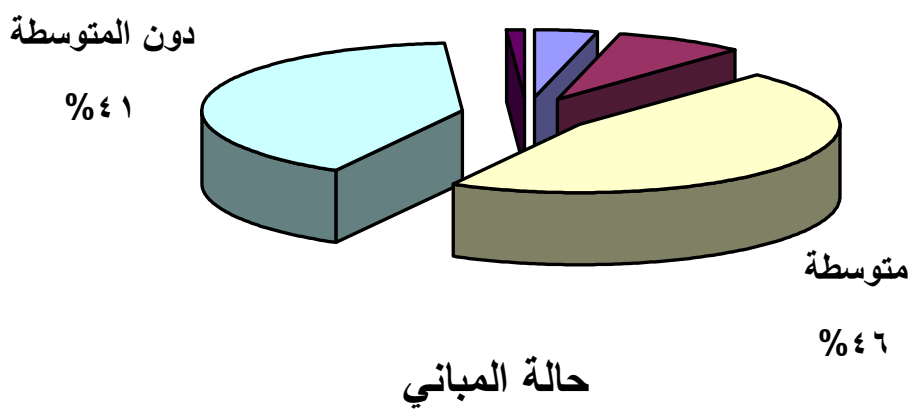

شكل رقم 7: رسم بياني يوضح النسبة المئوية لحالة المباني في منطقة الدراسة.

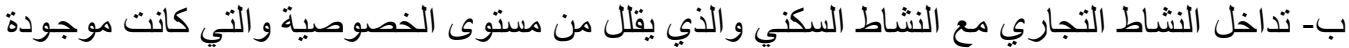

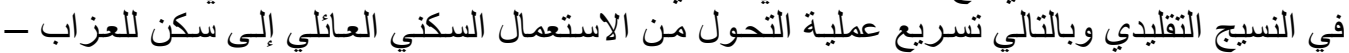

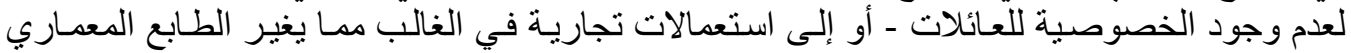
و الاجتماعي بشكل جذري.

ج- زيادة عملية البناء و المكننة تؤدي إلى زيادة سرعة تدهور المباني القائمة.

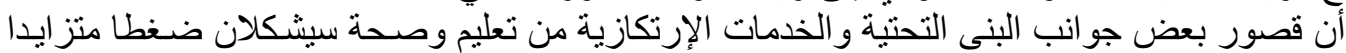

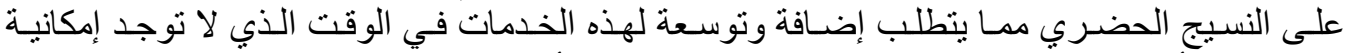

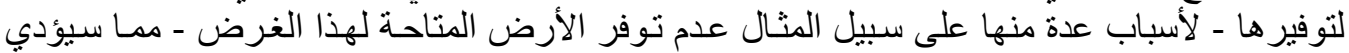

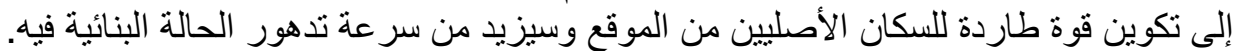

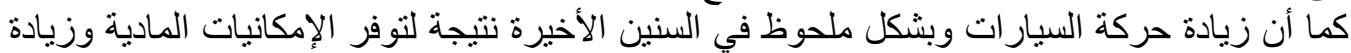
سفلتة وتبليط الطرق ساعد على تدهور الناحية البيئية والعمر انية وقلائل من مستوى الخصنية الخصوصية في الجزء السكني بشكل واضلح.

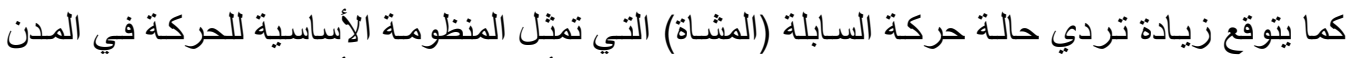

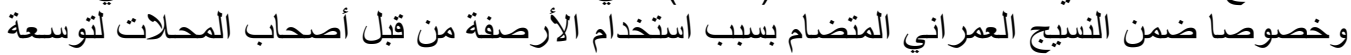

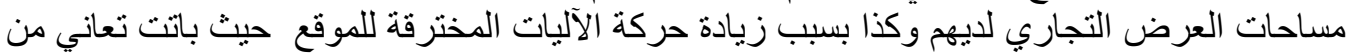

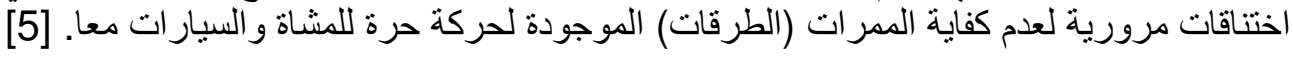




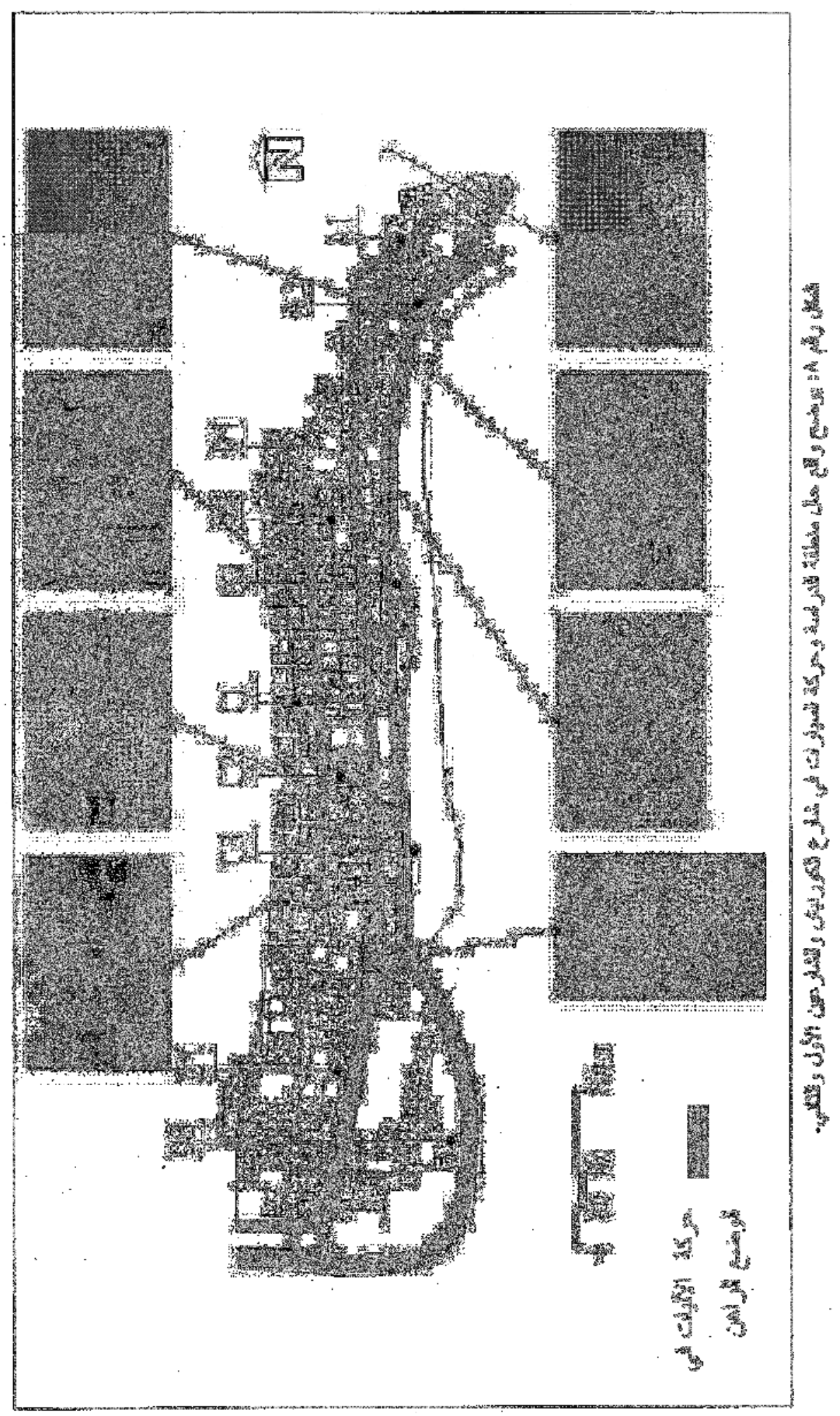




\section{8- التوصيات العامة لتطوير المنطقة}

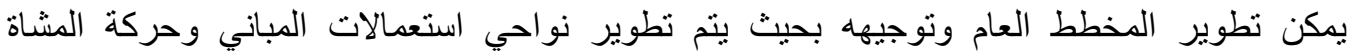

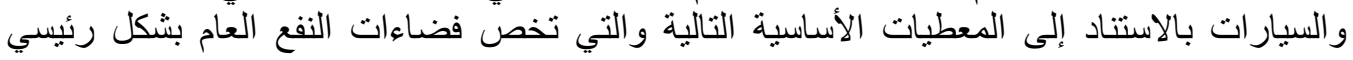
ؤـ أني: شارع الكورنيش ذو أهمية كبيرة لأنة يربط الأجز اء الثرقية من المدينة بالمناطق الأخرى ولكن

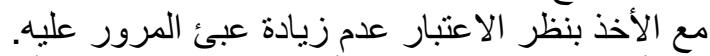

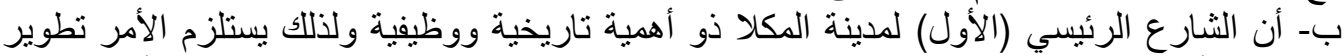

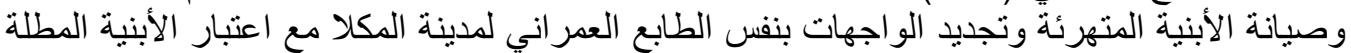

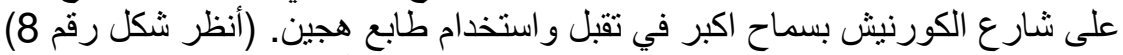

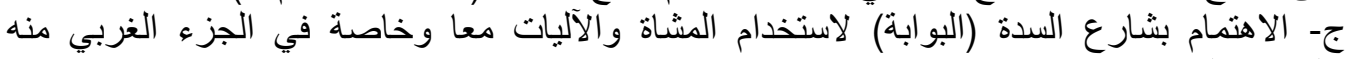

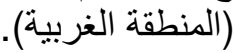

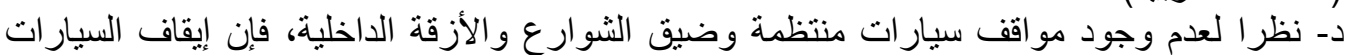

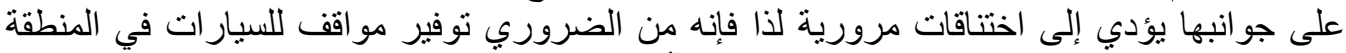

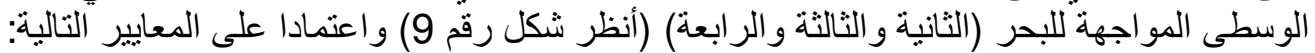
1- تخصيص موقفين للسيار ات كمقدار مقبول للمباني السكنية الداخلية و التي تشكل نسبة التبانية 30 -40 \% من الوحدات السكنية تقريبا. 2- تخصيص (300 (30 -4) مو اقف للسيار ات للمباني السكنية التجارية وبمعدل موقف واحد لكل 3- ضرورة توفير 200 3 مو اقف لكل 100م² من المباني التجارية.

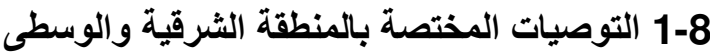

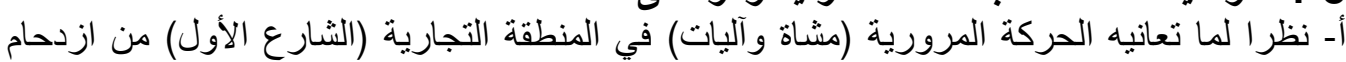

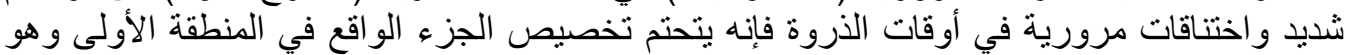

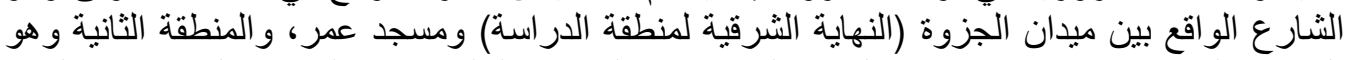

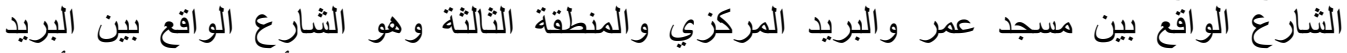

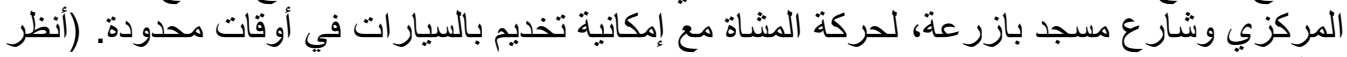

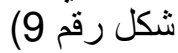

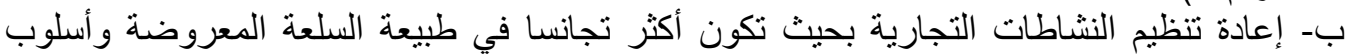

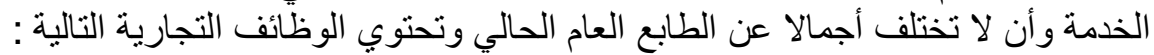

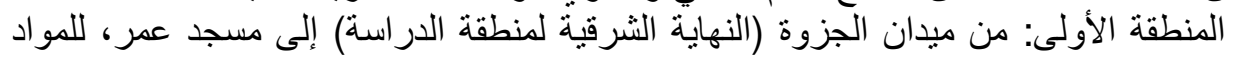

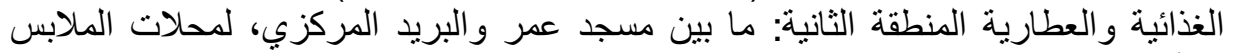
و الأقمشة. المنطقة الثالثة: ما بين البريد وحتى مسجد بازرعة، للمواد الكهربائية والأثاث و المفروشات

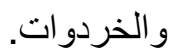
المنطقة الرابعة: المنطقة المحصورة بين مسجد بازرعة ومستشفى الأمومة والطفولة، للخدمات الطبية والصحية. ج- رصف أرضية الممثى بالحجر المحلي بحيث ينتمي إلى الطابع العام لمدينة المكلا وبحيث يضمن:

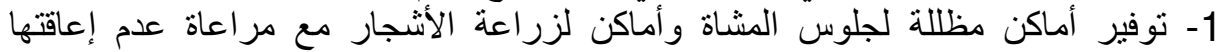
لحركتهم وحركة الرياح (زر اعة أثنار نخيل طويلة السيقان على سبيل المثال). 


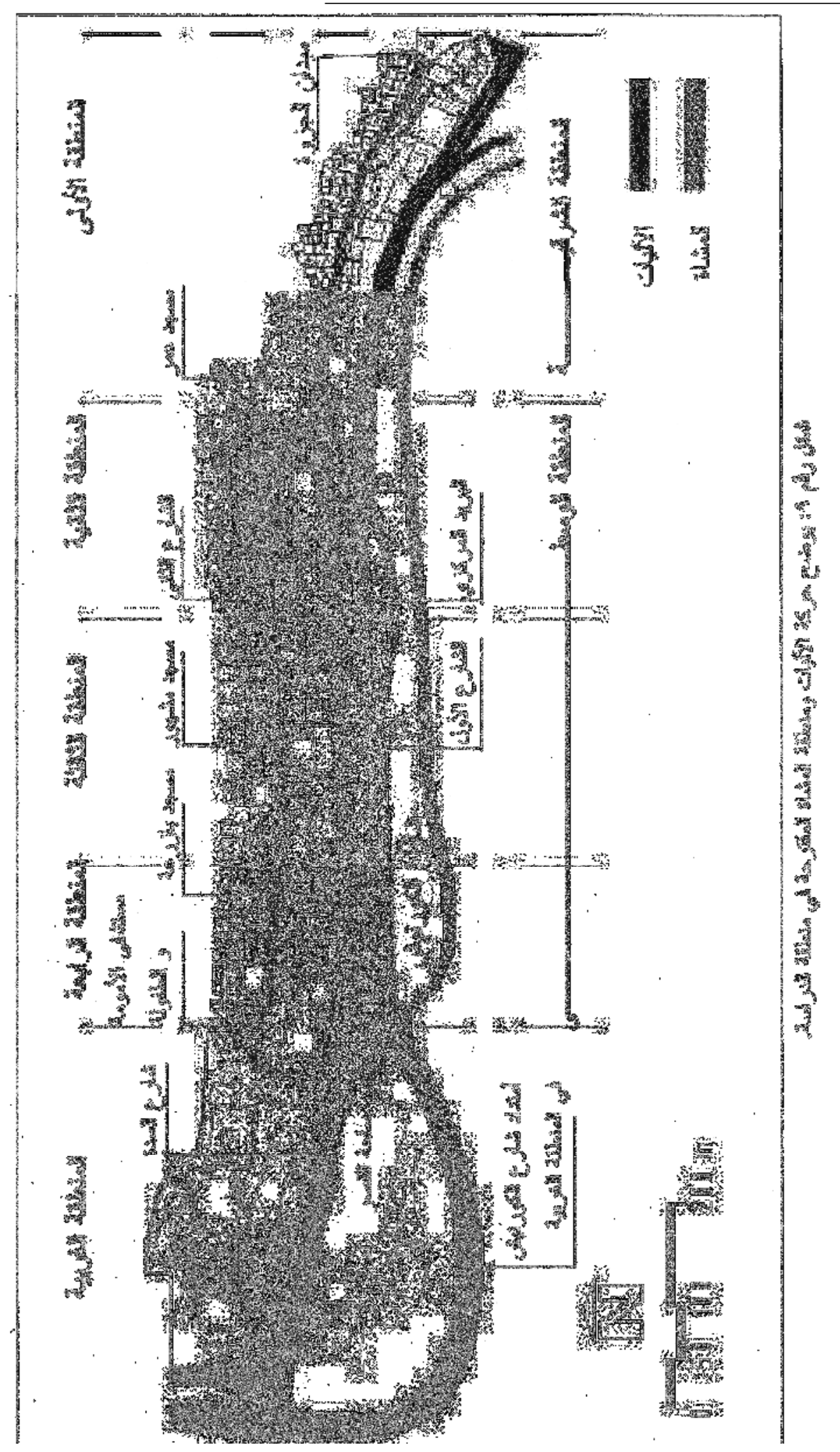


2- تمكين دخول سيار ات الطوارئ كالإسعاف و المطافئ و الثرطة وخدمات التنظيف وجمع

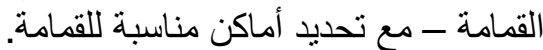

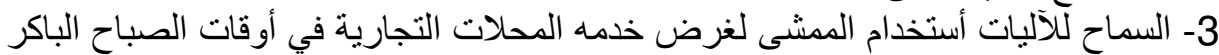

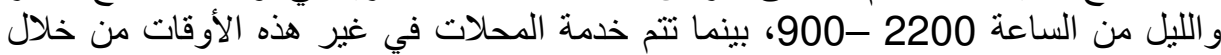

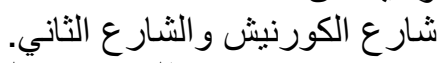

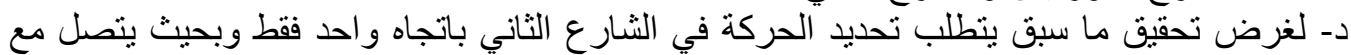

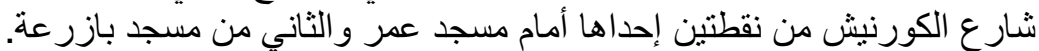

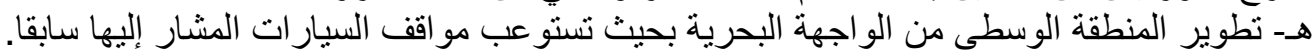

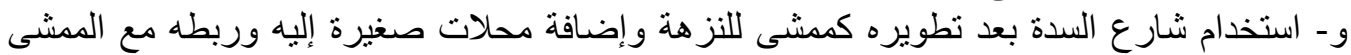
الرئيسي المقترح (الثار عارع الأول الحالي).

\section{2-8 التوصيات المختصة بالمنطقة الغربية} أ- حيث أن المنطقة تحوي مباني ومعالم ذات قيمة المئة نراثية وتاريخية فيوصى بتخصيص منطقة القصر

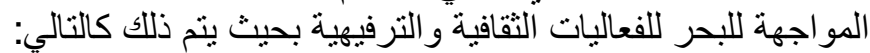

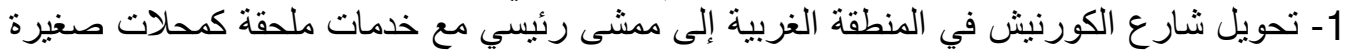
لتقديم المرطبات و المأكو لات الخفيفة وبحيث تشكل أماكن جيدة لتجمع واستجمام الناس. (أنظر شكل رقم

2- استخدام ساحة القصر و التي كانت تستخدم كساحة لاستعراض حرس السلطان، كساحة للفعاليات الرياضية والتي تحتاج المنطقة إليها بشدة مع تغيير وظائف الأبنية بالتندريج لتنفق مع الفعاليات الجئ الجديدة

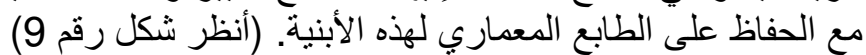

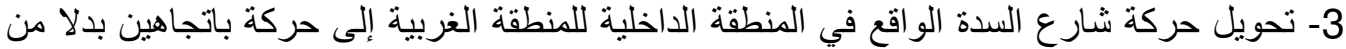

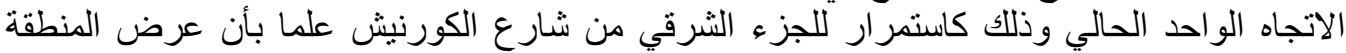

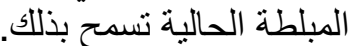

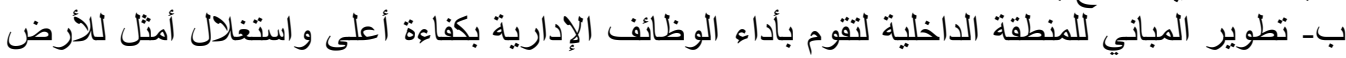

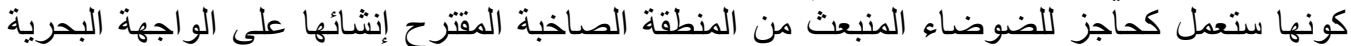

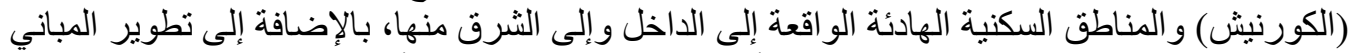

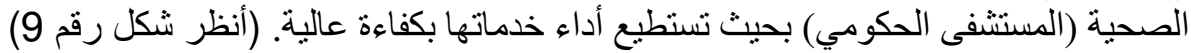

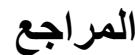

[1] الخضر، سالم عمر، وبن بدر، عبده عبداله، المكلا عروس البحر الحضرمية، صنعاء 1995 ،

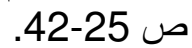
[2] الجوهي، محمد سالم سعيد، النمو الحضري في ساحل حضرموت (بين الأدة الثحر وحلة)، دراسة في

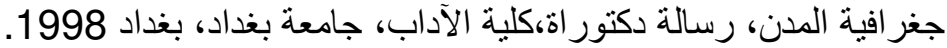

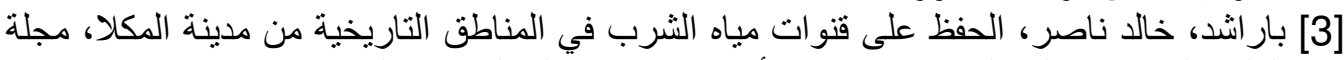

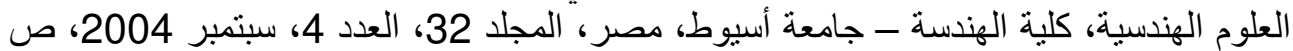

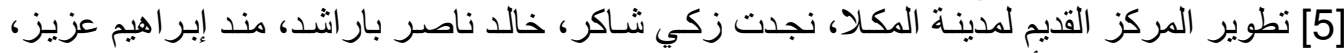
المؤتمر الهندسي الأول، ديسمبر 2000م، جامعة عدن. 